\title{
Will They Turn the Other Cheek? Decision Making and Victim's Religious Self-Identification
}

Craig A. Depken, II.

UNC-Charlotte

USA

\author{
Dennis P. Wilson * \\ Department of Economics \\ Western Kentucky University \\ USA
}

\section{ABSTRACT}

This paper examines the implications for potential victims of crime through religious self-identification. If a criminal can choose between an unidentified victim and a religiously self-identified individual, all else equal whom does he choose to victimize? We use religious self-identification to indicate that a person is a believer of Pascal's Wager while the criminal does not subscribe to the wager. We then derive game-theoretic decision matrices to depict the potential payoffs to a victim from resisting or conceding to the criminal activity. A similar analysis is conducted from the criminal's perspective to determine who to victimize. This analysis helps sheds light upon the decision of religiously motivated suicidal action and the decision of whom to victimize.

\section{Keywords: Applied Games, Economics of Religion, Pascal's Wager}

\section{Introduction}

Cognitive decision making is predicated upon one's understanding of their condition, their objectives, and their expectation of relevant outcomes. To assist in evaluating the relevant probability of outcomes agents glean evidence from situations, surroundings, and others who may influence or are involved directly in determining outcomes. As an example, a baseball hitter attempts to pick up the tendencies of a pitcher to improve his odds of getting a hit. An airline takes note of which competitors are most likely to respond quickly to route variations or fare adjustments to make appropriate strategic decisions. Likewise, potential thieves evaluate their surroundings; the number of potential witnesses or law enforcement agents, their objectives; the value of potential property or the comparable alternatives, and their expectation of a theft occurring without harm or resistance; the likelihood of the victim surrendering their belongings verses refusing to give in. Here we will attempt to apply game theory to evaluate the affect religious self-identification may have on a potential victim and a predator looking for a victim. Thus answering the specific question of does someone with religious beliefs, as defined through Pascal's Wager, make a better or worse target for criminal activity?

If a criminal can choose between an unidentified, secular victim and a religiously self- identified individual, all else equal whom does the aggressor choose to victimize? While those that are willing to identify themselves as religious are often perceived as patsies, the reward to those with religious beliefs and how the rewards are obtained are of critical importance in the victim's response to crime. We define religious self-identification to indicate that a person is a believer of Pascal's Wager while the criminal is assumed to not subscribe to the wager, an assumption which is later relaxed. We derive multiple basic game theoretic decision matrices to depict the potential payoffs to a victim from resisting or conceding to the criminal activity and similar analysis is conducted from the criminal's perspective to determine whom to victimize.

The suggested payoffs indicate that under Pascal's Wager, the criminal is more likely to victimize the unidentified individual because a religiously self-identified individual is more likely to resist and thus increase the cost to the assailant. To many, this result may seem counter-intuitive. Such resistance may lead to an escalation of violence in the commission of the crime which raises the expected cost of the crime, thus lowering the expected net benefit. However, by relaxing some of the assumptions of Pascal's Wager and the ceteris paribus conditions, it is possible to show the conditions under which a criminal 
is more likely to victimize the self-identified religious individual. Finally, we will argue that Pascal's Wager, in its popularly recognized form, may not be an appropriate representation of orthodox Christian beliefs.

\section{Pascal's Wager}

Decisions entail risks, losses and gains, and a priori assumption of probabilities. Blaise Pascal, a 17th century French mathematician and Christian apologist, recognized these elements and incorporated them into an argument for believing in God. Pascal states, "Let us weigh the gain and the loss in wagering that God is. Let us estimate these two chances. If you ga in, you gain all; if you lose, you lose nothing. Wager then without hesitation that.

He is." ${ }^{\prime \prime}$ This proposition has today become known as Pascal's Wager. In essence if the benefit from a decision is infinitely large, then regardless the probability of the supposition (as long as it is not zero), it is advantageous to select in favor of the supposition. Thus, Pascal argues that belief in God is prudent because the rewards are infinite and belief is a necessary condition for enjoying this inheritance.

This argument can be further illustrated with the following game theoretic decision matrix:

\section{Table 1: Pascal's Wager}

\begin{tabular}{|l|c|c|}
\hline & $\begin{array}{c}\text { God } \\
\text { Exists }\end{array}$ & $\begin{array}{l}\text { God Does Not } \\
\text { Exist }\end{array}$ \\
\hline Believe & $\infty$ & $f 3$ \\
\hline Secular & $f 2$ & $f 4$ \\
\hline
\end{tabular}

Each person is assumed to have the option of whether to believe in God's existence or to not believe as a secular nonChristian. In response there are two options: God exists or He does not exist. The payoffs are given in the respective boxes. Given that $f_{2}, f_{3}$, and $f_{4}$ are finite payoffs, then the expected utility can be represented as:

$$
\begin{aligned}
& E U(\text { Believe })=\infty \rho+f_{3}(1-\rho)=\infty \\
& E U(\text { Secular })=f_{2} \rho+f_{4}(1-\rho)
\end{aligned}
$$

If there is a non-zero probability of God's existence $(\rho>0)$ the optimal decision is to believe in the existence of God. The infinite utility of heaven trumps any finite reward of alternatives and thus belief is the prudent outcome. ${ }^{2}$

\section{Pascal's Wager and a Victims Decision}

As a potential victim of a crime, the victim often has a decision of resisting the assailant or conceding to the assailant's demands. This decision can have significant consequences in the response of the assailant. In return, the assailant may flee, releasing the victim with their possessions. The assailant may release the victim but still, make off with the booty. However, the assailant may become violent injuring or even killing the victim. To assess the decision of a potential victim, who is assumed to be a believer in Pascal's Wager, consider the following payoff matrix:

Table 2: Payoffs to a Believing Victim

\begin{tabular}{|l|l|l|l|c|}
\hline & Killed & Wounded & Released & $\begin{array}{l}\text { Released/ } \\
\text { Keep } \\
\text { Possessions }\end{array}$ \\
\hline Resist & $\infty \rho 1$ & $w \rho 3$ & $s \rho 5$ & $r \rho 7$ \\
\hline Concede & $\infty \rho 2$ & $w \rho 4$ & $s \rho 6$ & $r \rho 8$ \\
\hline
\end{tabular}

\footnotetext{
${ }^{1}$ Pascal, Blaise, Pascal's Pensees, (translated by W. F. Trader), New York: Dutton, 1958.

${ }^{2}$ There continues to be much debate concerning Pascal's Wager in economics (e.g, Montgomery, 1996)and outside economics (for example, Clifford, 1877; James, 1898; Mougin and Sober, 1994; Turner, 1968; Landsberg, 1971; and Carter, 2000, to name a few).
} 
The potential victim has two options: resist or concede; and there are four possible outcomes: the victim being killed, wounded, released without their possessions, and released with their possessions. It is reasonable to assume, though not necessary, that resistance makes being killed or wounded in commission of the crime of greater likelihood (i.e., $\rho_{1}>\rho_{2}$ and $\rho_{3}$ $>\rho_{4}$ ). Furthermore, the utility to the victim is finite for being released or wounded, but due to the victim's beliefs an infinite reward of heaven is received if the victim is killed, thus

$$
\mathrm{U}(w)<\mathrm{U}(s)<\mathrm{U}(r)<\mathrm{U}(\infty)
$$

The expected utility to the victim of a theft is

$$
\begin{aligned}
& E U(\text { Resist })=\infty \rho 1+w \rho 3+s \rho 5+r \rho 7 \\
& E U(\text { Concede })=\infty \rho 2+w \rho 4+s \rho 6+r \rho 8
\end{aligned}
$$

The expected utility of resistance is greater than the expected utility of concession if resistance provides a greater probability of death $\left(\rho_{1}>\rho_{2}\right)$. Since the infinite benefit of heaven promised to believers in Pascal's Wager is received upon one's death, then the escalation of the crime is encouraged by the victim in an attempt to collect the reward of their belief. While this fits with Pascal's Wager, it may run counter to many peoples expectation of how a religiously self-identified person might respond. Thus, if the value of life and everything associated with it is less than the infinite utility of heaven; one resists.

\section{Assailant's Decision}

In seeking potential victims, an assailant takes the decision matrix of a religiously self the identified believer in Pascal's Wager as given. The assailant must decide between a religiously self-identified person and a generic non-religious secular person. For now, it is further assumed that the assailant wields a potentially lethal weapon. If the assailant is risk-averse and not a believer in Pascal's Wager, they will consider the probability of success of their actions $(q)$, the reward if successful $(r)$, the cost if the victim resists $\left(c_{1}\right)$ versus if victim concedes $\left(c_{2}\right)$, and the relative probability of the victim resisting; $(\rho)$ for the believer and $(n)$ for the secular. ${ }^{3}$ From the previous discussion, a believer in Pascal's Wager will resist if resistance increases the likelihood of death. Since death is a possibility, $\rho$ can be assumed to equal 1.

The decision matrix for the assailant can be represented as follows:

Table 3: Payoffs to a Non-Believing Assailant

\begin{tabular}{|l|l|l|}
\hline & Resist & Concede \\
\hline Believer & $\rho\left(q r-c_{1}\right)$ & $(1-\rho)\left(q r-c_{2}\right)$ \\
\hline Secular & $n\left(q r-c_{1}\right)$ & $(1-n)\left(q r-c_{2}\right)$ \\
\hline
\end{tabular}

The relative expected values of the assailant can be presented as:

EU(victimizing a believer $)=q r-c 1$

$E U($ victimizing a secular $)=n(q r-c 1)+(1-n)(q r-c 2)$.

Thus the attacker will choose a secular non-believer only if

$$
\begin{array}{ll}
q r-c 1<n(q r-c 1)+ & (1-n)(q r-c 2) \\
\text { or } & c 1>c 2 .
\end{array}
$$

\footnotetext{
${ }^{3}$ This rational decision follows from the economics of crime literature originated by Becker, 1968; and continued by Blumstein and Rosenfeld, 1998; Dilulio, 1996; Levitt, 1996; Lott, 1997; and others.
} 
A secular non-believer is an optimal choice because the cost to the assailant is higher if the victim resists than if they concede $\left(c_{1}>c_{2}\right)$, the death of the victim is a perceived possibility, and the believer in Pascal's Wager will therefore resist. An assailant will only switch to victimizing a believer if the relative property value, and thus the reward if the theft is successful, is significantly higher for the believer than the secular victims:

$$
r_{1}>\frac{\mathbf{1}-\boldsymbol{n}}{\boldsymbol{q}}\left(c_{1}-c_{2}\right)+r_{2}
$$

The reward difference must provide a compensating differential for the criminal to make the cost of the victim resisting worth incurring.

The assailant's choice of a victim may, however, be altered if assailants themselves are believers in Pascal's Wager. If the cost incurred by the assailant from a victim's resistance extends to the potential death of the assailant, then the assailant's choice is based upon the victim most likely to escalate the altercation to the death of the assailant. As previously mentioned, since death to a religiously self-identified victim is a possibility, $\rho$, the probability of a believer resisting, can be assumed to equal 1. This guarantee of resistance makes religious victims an optimal target for a religiously convicted assailant.

Furthermore, a believing assailant has every incentive to pursue means of criminal activity that increases the probability of their own humanly demise. Hence, it is appropriate to refer to these as "suicide missions." While the result of these missions is not a guaranteed death, selecting a means and victim that increases this likelihood is optimal for the assailant. Thus, a potential victim's own belief in Pascal's Wager, or at least a perceived victim's belief by an assailant, makes the believer a more attractive target for a religiously self- identified aggressor.

\section{The decision when the Probability of Death is Zero}

Next, assume no deadly weapon is used in the commission of the crime and thus the victim's fatality is not a possibility. From Table $2, \rho l=0=\rho_{2}$. To further simplify the decision, assume that there is no significant utility difference for the victim between being released with or without their possessions. ${ }^{4}$ Thus Table 2 now becomes;

\begin{tabular}{|l|l|l|}
\hline & Wounded & Released \\
\hline Resist & $w \rho_{3}$ & $s \rho_{5}$ \\
\hline Concede & $w \rho_{4}$ & $s \rho_{6}$ \\
\hline
\end{tabular}

Hence, if resistance leads to a higher likelihood of being wounded, the concession has a higher likelihood of being released and visa-versa. Since $\mathrm{U}(w)<\mathrm{U}(s)$, expected utility is maximized by choosing the action that leads to the lowest probability of being wounded.

Sequentially this can be considered by the assailant in considering the decision matrix in Table 3 . If property values are allowed to differ, the relevant expected utility of the attacker now become

EU(victimizing a believer $)=\rho\left(q r_{1}-c_{1}\right)+(1-\rho)\left(q r_{2}-c_{2}\right)$
and
$E U($ victimizing a secular $)=n\left(q r_{1}-c_{1}\right)+(1-n)\left(q r_{2}-c_{2}\right)$.

An attacker will choose a victim based on the relative value of the property, the cost of the victim resists, and the relative probability of resistance. A believer is selected only if

\footnotetext{
${ }^{4}$ Alternatively, the victim's decision to resist or concede is based upon the perceived value of the property and the relative probability of maintaining control of their property while not being injured when resisting as compared to conceding.
} 


$$
r_{1}>r_{2}+\left(c_{1}-c_{2}\right) \frac{n-\rho}{q}
$$

While similar to the previous result, because death is not on the table, a believer may not resist $(\rho<1)$, thus the relative probability of resistance must be considered by the victim and weighed against the likelihood of success and the relative value of the booty.

\section{A Finite Value of Heaven}

By relaxing the assumption that everything is gained by the existence of God in Pascal's Wager and allowing the reward of heaven to be finite in nature, both the victim and the assailant's decisions are altered. A believing victim considers the value of their own life compared to the finite benefits gained from death and the rewards from his/her beliefs. If resistance increases the probability of the victim's demise, then resistance is only selected if a greater expected value, considering all relevant probabilities constant, exists in heaven than in life.

\begin{tabular}{|r|c|c|}
\hline & Killed & Released \\
\hline Resist & $f_{1} \rho_{1}$ & $f_{2}\left(1-\rho_{1}\right)$ \\
\hline Concede & $f_{1} \rho_{2}$ & $f_{2}\left(1-\rho_{2}\right)$ \\
\hline
\end{tabular}

If $\rho_{1}>\rho_{2}$, a victim will concede if $f_{2}>f_{1}$ and resist is $f_{1}>f_{2}$. This result is consistent regardless of whether the potential victim is a believer or not. The choice to resist or concede is determined by the relative probabilities of the outcome from the decision and the relative values of each outcome. While a relatively large value of heaven can explain resistance from a believing victim, a low expected value of one's future can explain resistance by a non-believer. Additionally, a high value of the property being targeted may lead to both a believer with a finite value of heaven and a non-believer resisting.

\section{Conclusions: Implications of Pascal's Wager}

The infinite reward of heaven promised in the popular form of Pascal's Wager provides an incentive for believers to engage in ever riskier behaviors, potentially to the point of being suicidal. Since the infinite nature of heaven dominates any finite utility of prolonged earthly existence, the economically best alternative is to pursue activities that risk one's life but do not jeopardize the rewards of heaven. The biblical verse of "Do not put the Lord your God to the test..." (Deut. 6.16, NIV), might indicate that rewards may be jeopardized with an unduly pursuit of death.

However, if the tenets of one's faith make the rewards of heaven dependent or enhanced by one's death, believers might pursue suicidal activities. Examples of such behavior would include religious "homicide bombers," David Koresh's Branch Davidians, Heaven's Gate, Jim Jones's The People's Temple, Joseph Di Mambro's The Solar Temple and others.

In many of these cases, the promised reward of heaven was finite and definable.

Since Pascal's Wager has been used as an apologetic tool for Christianity, why are the incentives of Pascal's Wager and the actions of modern Christians so different? Is it even an appropriate instrument for the defense of a Christian faith in God? It is believed the distinction may lie in the basis of the religious faith: grace-based versus works-based.

In graced-based religions such as Christianity, belief is not based upon the rewards of heaven but rather on the avoidance of hell and hence, the terms of repentance and salvation are prominent within Christian vernacular. While this does not change the outcome of Pascal's Wager, substituting the reward of one's faith away from infinite heaven toward an infinitely negative hell, does affect the incentives and value one places on their earthly existence. The prize of avoiding hell is granted upon repentance and baptism, not upon death, thus the engagement of riskier behavior in pursuit of one's death is no longer appropriate. Also, the methodology for evaluating life is transformed by faith in a grace-based religion. An individual's utility function is ostensibly replaced by what is believed to be God's utility function for them. This may include a calling to reduce or minimize their valuation of material possessions and/or to sacrifice one's earthly life but does not call for the active pursuit of terminating one's earthly life. 
On the other hand, works-based religious beliefs may or may not be based on the avoidance of hell. Upon an individual's death, their positive deeds are held in the balance of their ill deeds. If the sum effect of the positive deeds is outweighed by the negative deeds, the individual is found wanting and heaven is denied and hell maybe the due punishment. If the positive deeds outweigh the negative deeds, access to heaven is granted. Either way, rewards are determined upon one's death, not guaranteed before death. If an individual is certain their positive deeds outweigh their negative deeds that individual might seek to expedite their reward. For such individuals, the results are the same as in Pascal's Wager. Thus, a believer might undertake risky behavior to increase the likelihood of death in an attempt to collect their heavenly reward.

If however, the balance of an individual's needs is not favorable or is unknown, then the punishment will be administered upon death and they will choose to avoid risky/potentially deadly behavior. To avoid this unknown/potential punishment, some works-based faiths offer martyrdom as a means of guaranteeing that an individual's deeds are net positive.

Given the inconsistency between the behavior of Christians and the incentives provided by Pascal's Wager, the wager does not seem appropriately applied to Christian apologetics. It may, however, be a means of explaining behavior in other works-based religions.

\section{References}

Becker, Gary (1968). "Crime and Punishment: An Economic Approach.” Journal of Political Economy 72: 169-217.

Blumstein, Alfred and Richard Rosenfeld (1998). "Explaining recent Trends in U.S. Homicide Rates.” Journal of Criminal Law and Criminology 88:1175-1216.

Carter, Alan (2000). On Pascal's Wager, or Why All Bets Are Off." The Philosophical Quarterly, 50: 22-7.

Clifford, W. (1877). "The Ethics of Belief." In Lectures and Essays, volume 2. London: Macmillan, 177-211.

DiIulio, John J. (1996). "Help Wanted: Economists, Crime and Public Policy." The Journal of Economic Perspectives 10:3-24.

James, W. (1897). "The Will to Believe." In The Will to Believe and Other Essays in Popular Philosophy. New York: Longmans, 1-31.

Landsberg, P.T. (1971) "Gambling On God.” Mind 80-100-104.

Levitt, Steven (1996). "The Effect of Prison Population Size on Crime Rates: Evidence from Prison Overcrowding Litigation." Quarterly Journal of Economics 111: 319-352.

Lott, John R. Jr. (1997). “Crime, Deterrence, and Right-to-Carry Concealed Handguns.” Journal of Legal Studies 26: 1-68. Mougin, Gregory and Elliot Sober (1994). "Betting Against Pascal's Wager.” Nous 28: 382-395.

The Holy Bible, New International Version (2011), Biblica, Inc., Colorado Springs, Colorado.

Pascal, Blaise (1662) Pensees. Translated by W. Trotter, New York: J.M. Dent Co. 1958. 233-241.

Turner, Merle (1968). "Deciding on God-The Bayesian Support of Pascal's Wager." Philosophy and Phenomenological Research 29: 84-90. 